\title{
Social Differences in Infant Mortality in the Norwegian Parish Asker and Bærum 1814-1878
}

\author{
Eli Fure
}

B $y$ the turn of the century 1700/1800 less than one in five Norwegian children died before their first birthday. The average hides variations among regions and over time. ${ }^{2}$ Infant mortality had, at least in some areas, started its secular decline from the end of the 18 th century. ${ }^{3}$ Neither in Norway nor in other countries have the causes of decline been definitively identified. One hypothesis has been that the decline in mortality was associated with an increase in prosperity. One would, therefore, expect that infant mortality was higher in the poorer classes, at least during the initial stage of the decline in infant mortality.

Researchers have published data on infant mortality according to social groups in some Norwegian family reconstitution studies from different parishes. Usually there are two groups: one consists of farmers, whereas the other is a mixed group of cotters, crofters, laborers, workers, fishermen and sailors. Family reconstitution is very time-consuming work. The results for individual parishes often do not consist of a large number of cases, and the differences found have not been subjected to statistical testing. This makes it difficult to interpret the results, and the researchers are usually reluctant to make substantial conclusions. One exception is a study not based on study of a single parish, but rather on linkage between records from church registers from 45 randomly chosen parishes for two to five years around

1 E. Fure, "Spedbarnsdødelighet og sosiale forskjeller i Asker og Bærum 1814-1878. En metode for studier på individnivå," Heimen, 37 (2000). A Norwegian version of this paper was first published here. volume.

2 G. Thorvaldsen, "Rural Infant Mortality in Nineteenth Century Norway" in this

3 E. Fure, "Nedgangen i dødeligheten i Asker og Bærum 1733-1878," Heimen, 36 (1999). 
1800 and the 1801 census. The results of this study indicate that infant mortality was highest in the most affluent social group. ${ }^{4}$

\section{Method}

\section{Family Reconstitution and Life Tables}

In order to analyze historical mortality at the individual level, the data set has to consist of some kind of linked records. Information about a person must be retrieved from at least two different sources. The usual procedure, family reconstitution, was developed by French demographers almost 50 years ago. The method consists in linking entries in marriage registers to those in the baptism and burial registers, thus reconstituting families onto "family sheets". The information on these sheets is subsequently used for demographic analyses. ${ }^{5}$ For mortality studies, life tables are constructed; the number of births, deaths and the number remaining alive at increasing ages are tabulated and then analyzed.

The data set from Asker and Bærum is not a family reconstitution. An interactive record linking system was used in order to link computerized individual event records from church records, censuses and land registers into life courses. The units are persons, not families, but there are connections between parents and children, so that it is possible to use information about the parents in the analysis of infant mortality.

An efficient way of exploiting the information in life tables is to combine it with regression analysis, which makes it easier to assess the effect of different variables on mortality. This type of regression technique is used for many purposes in different types of research and is known under several names, such as event history analysis or survival analysis, which is the term that will be used here.

4 R. Engelsen, "Mortalitetsdebatten og sosiale skilnader i mortalitet," Historisk tidsskrift 2 (1983), 161-202.

5 M. Fleury, and L. Henry, Des registres paroissiaux à l'histoire de la population. Manuel de dépouillement et d'exploitation de l'état civil ancien (Paris, 1956). 


\section{Survival Analysis}

Survival analysis was designed for longitudinal data on the occurrence of events, that is a qualitative change that can be constituted in time, a transition from one discrete stage to another. In this case the events are deaths. The death rate resembles the death probability, which is the probability of dying at a particular age interval, but they are not the same. The death rate has the form number of events per interval of time: it is a conditional probability, and only the individuals who have survived to the beginning of the interval are considered. For computing the death rate, we need not only the number of deaths, but also the time until the deaths occur. The shorter the time, the higher the death rate.

The main advantage of survival analysis is that it allows for censoring. If a person does not die during the age of interest, he or she is censored. All the children who survive their first birthday are censored in studies of infant mortality. Not all types of censoring are acceptable in survival analysis, as some may give biased results. It is important to know how the persons enter into and leave the analysis. Censoring is not a concept in family reconstitution, but there are rules about how to use the data for different types of demographic analyses.

\section{Censoring and Family Reconstitution}

It is always easier to know the number of deaths in a population, than to know the exact size of the population. Migration disturbs mortality analyses because it makes it difficult to know the size of the population at risk. In order to cope with this problem, the creators of the family reconstitution method assume that children stay with their families until they are 10 or 15 years old. If it is clear that the family lived within the parish at a given point in time, it is assumed that the children also lived in the parish at that time. The basic rule is not to use the same type of event that is studied, to decide whether the family still lived in the parish. In studies of infant mortality one does not use the dates for infant deaths as final points of observation of families.

Proof for the presence of a family can be that the parents are found in a census or in a church register as parents for a baptized or buried child (if it is not an infant). Figure 1 shows how different types of events can be used to decide which children should be included in the analysis of infant mortality. Solid lines show the periods where the different persons A-F can be used for mortality analysis according to family reconstitution; dotted lines show periods that cannot be used. Persons A through C survived their first birthdays, while person $\mathrm{D}$ died. They can all be used, as we know that their families were present in the parish thereafter. The persons $\mathrm{E}$ and $\mathrm{F}$ cannot be used. We know the births of $\mathrm{E}$ and $\mathrm{F}$, and the death of $\mathrm{E}$, but nothing 
about their families. If $\mathrm{E}$ is included in the analysis, but not $\mathrm{F}$, infant mortality will be overestimated.

It has been maintained that the problem of migration in infant mortality studies is negligible because we can control migration through information about the presence of other members of the family, but the data from traditional family reconstitution studies are not exploited as efficiently as possible. There are important differences in the number of births and the number entered in the life tables which usually include ages up to 15 . In her Ph.D. thesis, Sølvi Sogner shows that 3,851 children were baptized during the period 1734-1828. Less than $65 \%$ of these enter the life table. ${ }^{6}$ In another study, only $52 \%$ of the baptized children are used in the life table. ${ }^{7}$ The possible effect this had on selection should be discussed.

This method meant that only births that occurred up to 15 years before the cutoff date of the study are used. For example, if the final year chosen was 1800, children born in 1786 or later are not included. This choice was probably justified in order to save labor as the life tables were created manually. This effect is, however, selection over time. If time is not crucial in the study, this selection is not critical.

Another problem is that children born out of wedlock are often excluded from family reconstitution studies. Since children have higher mortality, this exclusion means that the total mortality rates will be downward biased. Further characteristics of those who do not enter the life tables are unknown, and therefore, it is difficult to discuss how the mortality rates might be affected.

The traditional method leads to a loss of information, both because family reconstitution is a manual method, where each different sorting of the cards is time consuming, and because traditional life tables, and not survival analysis, are used. In survival analysis the individuals are present until the death occurs or until the time when the individual no longer takes part in the analysis. In life table analysis the individuals are used until they die or until they pass certain predefined age intervals. If we know the date of birth for a person and know that he or she was alive at the time of a census some months later and then disappears, he or she is not used in life tables based on family reconstitution. In survival analysis the person can be used up to the last time we know that he or she was alive. With the help of the computer, we can compare mortality rates based on different assumptions of survival times.

6 S. Sogner, Folkevekst og flytting (Oslo, 1979), 306, 387.

7 H. B. Randsborg, Befolkningsutviklingen i Bø i Telemark 1727-1815. Cand. philol. thesis, (University of Oslo, 1979). 
Figure 1. Conservative censoring. Solid lines show examples of life courses to be included, dotted lines shows life courses to be excluded, according to the family reconstruction method

Date of birth

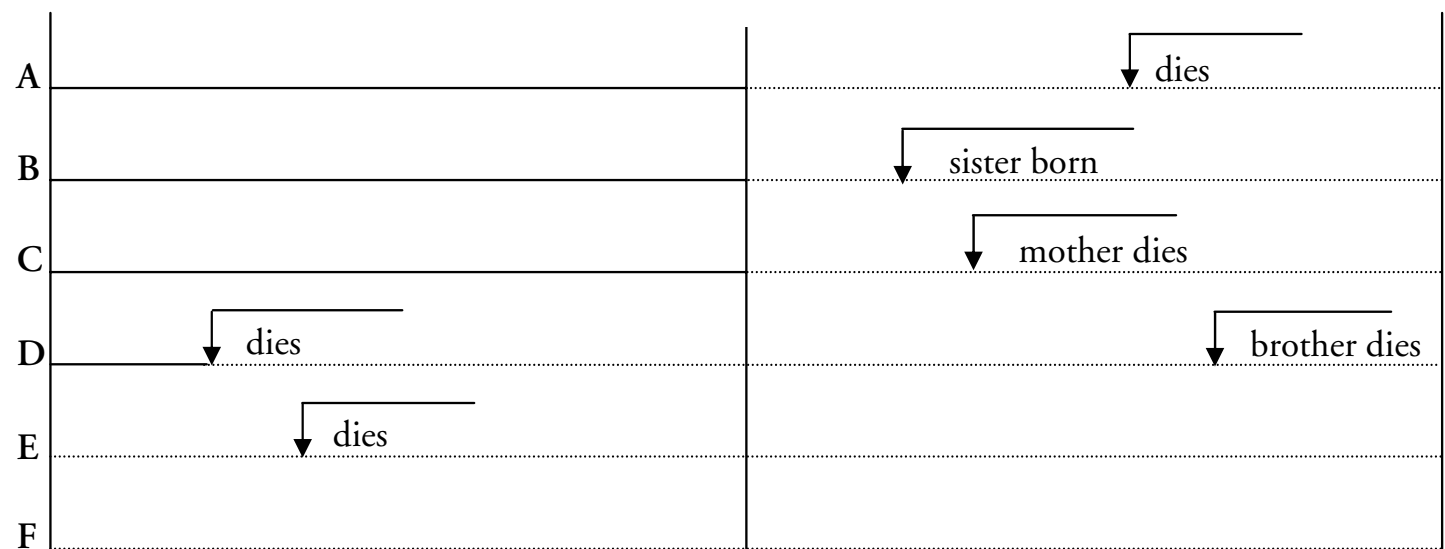

Figure 2. Radical censoring. Solid lines show examples of life courses to be included, dotted lines show life courses to be excluded, according to the assumption that children survive infancy unless a death record is found.

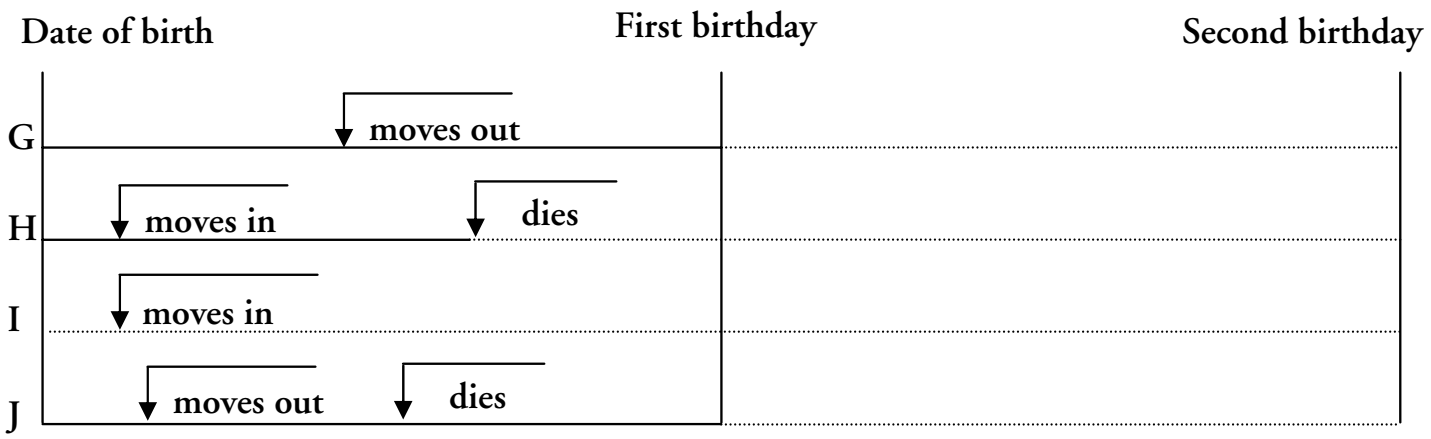




\section{Censoring Individually Linked Life Courses}

In my data set, where the basic units are individuals and not families, the question of survival times must also be solved. ${ }^{8}$ First of all, the baptized children, just under 15,000, were selected. To these were added about 400 children found only in the burial lists. Most of these 400 were born in Asker and Bærum, but died so shortly after their birth that they missed baptism in church. The main problem is that we do not know if, or when, the children moved out of the parish. Two different assumptions will be tested and the results will be compared. The most radical solution is to assume that everybody survived infancy, whether they moved out of the parish or not, unless we have a death record before their first birthday. Some possible cases are shown in Figure 2. Solid lines show accepted life courses with the most radical assumption; dotted lines show life courses that cannot be used. The persons $\mathrm{G}$ and $\mathrm{J}$ are possible types of out-migrants, as was $\mathrm{F}$ in Figure 1, that is, persons for whom we have only information on baptism. Both $G$ and J move out, whereas J dies in infancy after out-migration. With the radical assumption, both $\mathrm{G}$ and $\mathrm{J}$ are considered to be alive on their birthdays.

The persons $\mathrm{H}$ and I are in-migrants after baptism, that is a type of person not included in Figure 1. The person $\mathrm{H}$ is included in the analysis until his or her death, while the person I is not included in the analysis at all. The possible loss of survival time for I is assumed to be compensated by the excess survival time of J. The radical assumption will make the best use of the data and should be chosen if it can be proven to be reasonable.

One year is a short period, and families with small children were less likely to move than unmarried young people. If the families moved, it is highly improbable that the migration was related to the health condition or mortality risk of the child.

The 400 infants who were registered in the burial records only include children who were not born in Asker and Bærum, but who moved in shortly after their birth. A sample where the families of these infants were studied in detail suggests that about $25 \%$ of them were born outside the parish. These are included in the analysis because they were probably subject to the same causes of death as the children who were born in the parish.

The radical assumption is thus that the number of deaths among the outmigrants was about the same as the number of deaths among the in-migrants, or, in other words, that the out- and in-migration rates were equal and that the mortality rates were equal for out- and in-migrants.

8 The data set consists of linked individual event record from the censuses in 1801, 1815, 1825, 1835 and 1865, all of which are nominative in Asker and Bærum; baptismal, marriage and burial records from the church registers for the period 1814-1878, as well as records from land registers from 1802, 1826, 1838, 1866 and 1888. 
A more conservative approach is to follow the principles of family reconstitution as far as possible. If it can be documented that the family still lived in the parish, we can safely assume that their infants lived with them. This is fairly obvious for children born in wedlock, but cannot be assumed for children born out of wedlock. An unmarried mother could leave her child with a wet nurse, and thus we cannot be sure that the child lived in the same parish as the mother.

For each mother and father the final individual event record was located, and, if the record was for an event other than the death of the infant, then the date of the event was chosen as the end of the observation of the parent. Since the final registration is from 1878, there was little time for parents of children born in the late 1870 s to have other records as proof of their existence in the parish. This procedure leads to a selective loss of these late-born infants, whether they died or not. The types of life courses included in the analysis are those of the persons A-D in Figure 1.

\section{Explanatory Variables - Hypotheses and Coding}

\section{Sex, Year of Birth, Marital Status of Parents and Residence}

Information on sex, birth year, whether the birth was within or out of wedlock and residence are variables with values for almost all the children. The place of birth or the place of death for the 400 who were not in the baptism lists is interpreted as residence. Sex is either given explicitly in the church records, or may be deduced from the first names.

Boys normally have higher mortality than girls, so I expect this also to be true for the children in Asker and Bærum. In an earlier article where the data was based on aggregate figures from the church registers, I have found a decline in infant mortality, ' so I assume that the method of survival analysis will show a decline as well.

The baptismal records always state whether a child was born within or out of wedlock. Altogether seven percent of the children were born out of wedlock. Among the 400 from the burial lists, $14 \%$ were born outside marriage. The total number of illegitimate children born was 1,100 . It is well-known that children born out of wedlock have higher mortality than those born within marriage, but the difference varies in historical studies.

9 E. Fure, "Nedgangen i dødeligheten i Asker og Bærum 1733-1878," Heimen, 36 (1999). 
The economy in Asker and Bærum was based primarily on agriculture, but there were also families who earned their living from an iron foundry. It would be interesting to see if children who lived on the foundry premises had a higher or lower mortality than those who lived elsewhere. Slightly more than 1,000 children were born in the foundry areas.

Epidemic diseases might spread more easily in the more densely populated foundry areas, and this would lead to higher mortality. On the other hand, infant mortality was lower among workers in the foundry industry in Sweden. This has been explained by the paternalistic spirit of the foundry owners who supplied the workers families with medical care. Breast-feeding was reported to have been more common in iron foundry communities than in adjacent rural communities. ${ }^{10}$

In Asker and Bærum there is no evidence of better health care for the foundry workers than for the other inhabitants in the parish. The low rate of infant mortality in the parish cannot be explained otherwise than with the existence of a widespread practice of breast-feeding before the outset of the decline in infant mortality.

In addition to the foundries there was also a village, Sandvika, inhabited by fishermen and workers. Sandvika was more densely populated than the rural districts. Infant mortality was at the time higher in urban than in rural areas, but Sandvika was quite small. Only 300 children were born in the village. If the numbers are not too small, I will expect higher mortality in Sandvika.

\section{Social Groups}

When the question about the relationship between infant mortality and social class is raised in historical studies, the underlying hypothesis has often been inspired by the present world situation where poorer countries have higher death rates. The hypothesis presupposes that there is knowledge about factors that increase the survival chances of infants, and that these factors, such as cleanliness, proper nourishment, and adequate housing and clothing, are correlated with prosperity.

The best nourishment for an infant is mother's milk. It is important to start the breast-feeding as early as possible and to avoid supplementary food the first months. Breast-feeding strengthens the immune system of the child. Supplementary food may be difficult for the child to digest, or even worse, it may be contaminated. Both the intensity of the breast-feeding and the length of the breast-feeding period are important for child survival. Breast-feeding practice is perhaps more a question of culture than of prosperity. A Swedish study has shown that infant mortality was

10 J. Sundin, "Culture, Class, and Infant Mortality during the Swedish Mortality Transition, 1750-1850," Social Science History, 19 (1995), 120-121. 
higher in farmers' families than in the families of landless agricultural workers, because breast-feeding was more widespread among the latter.

Housing conditions were better for farmers than for the lower social class. For the adult population respiratory diseases were a major cause of death in Asker and Bærum, and this was probably also the case for infants. Cause of death was often not stated for children, but the mortality was much higher during the winter than in summer. ${ }^{11}$ All other things being equal, this should imply that the farmers' children were better protected and had lower mortality. Greater exposure to infectious diseases could counter this effect. It is not certain that farmers' households with many members were more favorable environments than the smaller households of the landless class. In his analysis of the 45 parishes around 1800, Engelsen found higher infant mortality among the more prosperous. He attributes this to their larger households.

Cleanliness and, in particular, clean water are important to avoid gastro-intestinal diseases. In historical populations, however, there is always the question as to whether people realized the importance of clean water. The significance of this factor is difficult to assess in Asker and Bærum. The fact that mortality was higher during winter than during summer for infants indicates that respiratory diseases were more important than diseases related to cleanliness.

Thus, it is not obvious that infant mortality is related to prosperity or social class. As if this was not enough, it is also difficult to interpret information about social position. The sources do not give consistent types of data about the father; occupation, trade, or social class may be given, or nothing at all. There will often, but not always, be a correlation between these pieces of information, but here. I assume there is a correlation between high social position and prosperity.

The coding was done in two steps. First, a fairly detailed coding of occupations was completed which resembles the codes in the machine-readable version of the 1801-census for the whole country. ${ }^{12}$ Each source was coded separately. Thus different codes could be given to the same occupation if found in two different sources. This was useful because some occupations had higher status at the beginning than at the end of the period. In some sources there was an abundance of occupations or trades; in other sources, the paucity was just as remarkable. Altogether 240 codes were employed, which is an amount that is impossible to use in any analysis. The level of detail was chosen in order to get an overview of the content in the data set.

The next step was to group these codes into three main categories for social class: an upper, a middle and a lower class. The idea was to group farmers in the upper

11 E. Fure, "Dødsårsaker i Asker and Bærum på 1800-tallet. En kildekritisk undersøkelse," Heimen, 36 (1998).

12 J. Oldervoll, 1801-prosjektet, Databehandling av ei folketeljing, (Historisk institutt, University of Bergen, 1978), 14-22. 
class; craftsmen, shipmasters and innkeepers in the middle class; and landless laborers, craftsmen, sailors, fishermen and servants in the lower class. Separating the middle from the lower class was not easy. The craftsmen were the most difficult group to handle. Therefore, the lower and the middle class were grouped together.

The coding in itself is complicated. Additional problems included choosing which of several codes a person should be assigned during a lifetime and how to treat those cases where there was no information. The best choice would be to use information given in connection with the baptism of the child, but this is impossible, since $30 \%$ of the baptisms lacked information about social class. I had to use information about the social position of the father from all the sources where such information was given, before, at or after the baptism. The advantage is that more fathers can be classified socially; the disadvantage is that social mobility is not considered. Sometimes there is real social mobility, but sometimes it is only apparent, as for the servant category. Farmers' children were often servants in their youth, which meant nothing for their later social classification.

Analytically it may be a problem to use information after the birth or death of the child as an explanatory variable. This is so if the information is dependent upon the preceding event. In this case it is not likely that the death or survival of a child had an effect upon the social classification of the father.

I tried to make a general code for the whole lifespan of a person in two ways. The first was to make some kind of a personal profile for each person. For some persons, there were many codes; for others few or none. The result was not very encouraging. Many had an unsystematic mixture of codes for high and low class during their lifetime. Some had, of course, been socially mobile, but the overall impression was that the social coding, laborious as it had been, nevertheless contained errors. It is difficult to assess the amount of errors, the probability of getting a wrong code for each person increases for each time there is a piece of information to be coded during the life-course.

Another method was, therefore, chosen. To solve the problem that a person was designated as a farmer, regardless of how much land he owned or controlled, information from the land registers was useful. If the size of the farm was greater than 500 ares ( 12.5 acres), or the taxation of the farm exceeded one daler in the land register, the social classification of the owner was high. In other countries and in Norway today 500 ares is a small farm, but this size has been used as the dividing line between large and small farms in earlier Norwegian social history studies. ${ }^{13}$

In the final coding all codes for each person were registered so that a high social code gave one plus point, while a low social code gave one minus point.

13 T. Pryser, Thranittene $i$ Ullensaker: En sosialhistorisk analyse (Cand. philol thesis, University of Oslo, 1974). 
Information from the land registers was given double weight, because it was less ambiguous than the information from censuses and church records and because land ownership was very important in an agricultural society. Finally, the number of points were added. Those who had a positive number of points were categorized as the high social class, where a negative sum meant inclusion in the lower group. Cases where there was no information about social class, or where the points canceled out each other, resulting in a sum of zero, were not coded at all. In all $20 \%$ were excluded, while of those who were coded, $20 \%$ went to the higher class, and $80 \%$ to the lower. This process was completed for all the persons in the data set; for the fathers the proportion coded was higher, more than $95 \%$.

\section{Control of Data Quality - the Stillborn Children}

In the family reconstitution method a family context is created for each individual. This context enables the researcher to assess the quality of the data, i.e. underregistration or errors in the sources and to make corrections so that the finally reconstituted families are as complete as possible. My data set underwent a quality control with several types of testing during the record linkage process. ${ }^{14}$

The definition of stillbirths changed during the 19th century, and the church records reveal inconsistent registration practices. Altogether 462 cases were stated as stillbirths and are thus omitted from the analysis, but there is also a problem with the children who were reported as dying on the day of birth or the day after. These children are not evenly distributed in the church records. Does this mean that some of the stillbirths really were live births? The stillbirths and the infants who died before they were two days old were added for each year. The new distribution was not smoother than for the stillbirths alone.

In order to get comparable data, another solution was chosen. All stillbirths and all children who died before they were two days old, about 150 infants, were excluded from the analysis.

14 E. Fure, "Interactive Record Linkage: The Cumulative Construction of Life Courses," Demographic Research, http://www.demographic-research.org/Volumes/Vol3/11. 
Table 1. The relative risk of infant mortality in Asker and Bærum 1814-1878 according to alternative methods of censoring. Summary table of four different outputs. The complete tables are in the appendix.

\begin{tabular}{lllllll}
\hline \multicolumn{2}{l}{ Method for censoring of data } & \multicolumn{5}{l}{ Conservative } \\
\hline & Radical & & & Risk ratio & P-value & $\mathrm{N}$ \\
\hline Variable & Risk ratio & P-value & $\mathrm{N}$ & 0.0200 & 12896 \\
\hline Male & 1.17 & 0.0040 & 14793 & 1.15 & 0.0004 & 12896 \\
Out of wedlock & 1.94 & 0.0001 & 14793 & 1.46 & 0.0001 & 12896 \\
Year of birth & 0.99 & 0.0001 & 14793 & 0.99 & 0.6302 & 12896 \\
Foundry & 0.93 & 0.5098 & 14793 & 0.94 & 0.6244 & 12896 \\
Sandvika & 1.23 & 0.2370 & 14793 & 1.10 & 0.6905 & 12501 \\
High social class & 0.94 & 0.3630 & 14087 & 0.97 &
\end{tabular}

Sources: See note 8.

\section{The Results}

Within survival analysis there are several different statistical models. My choice was a Cox regression model which is a combination of the proportional hazard model and the estimation method of maximum partial likelihood. I used the statistical package $S A S^{\circledR}$ System for the analysis. ${ }^{15}$ One of the important advantages of Cox regression is that it is not necessary to choose a particular probability distribution to represent survival times, therefore it is quite robust.

For indicator (dummy) variables with values of 1 and 0 , the risk ratio can be interpreted as the ratio of the estimated risk for those with a value of 1 to the estimated rate for those with a value of 0 (controlling for other variables). The $p$-value refers to Wald chi-square tests for the null hypothesis that each coefficient is equal to 0 .

Table 1 shows the results for the two alternative ways of censoring the data. The first is the radical, where all the infants not registered as buried before their first birthday are treated as surviving, and thus are censored at their first birthday. The second is the conservative, where the surviving children must have one of the parents living in the parish after their first birthday. Table 1 is an abbreviated combination of four different analyses: two ways of censoring, one with and one without social group as a variable. The reason for doing separate analyses when the social group is used as a variable is that $S A S^{\circledR}$ omits observations without a complete set of values in the analysis. Social group is the only variable where several

15 D. Cox, "Regression Models and Life Tables," Journal of the Royal Statistical Society, Series B (1972). The method is also described in Paul D. Allison, Survival Analysis Using the SAS® System, A Practical Guide (Cary, NC, 1995). 
observations do not have a value. When this variable is used, the number of observations is reduced. The results for each analysis are shown in detail in the appendix.

With the radical censoring, 700 observations lack information on social status; with the conservative the loss is less, 400 observations. Children born out of wedlock often lack information about their fathers, and many of these children are already excluded with the conservative censoring.

\section{Radical Censoring}

The results obtained by radical censoring are shown in the left part of Table 1 . Males had, as expected, a higher mortality rate than females: the estimate is $17 \%$ higher. For each year infant mortality declined one percent, and the death risk was almost twice as high for children born out of wedlock as those born within. The two variables for residence do not show significant results.

If the social group is taken into the analysis, the estimate for the increased mortality risk for illegitimate children is reduced to 1.7. There is a positive correlation between belonging to the lower social class and being born outside marriage, but many of the children born out of wedlock lack information on social class and are lost from the analysis. The variable itself, social group, does not seem to have an effect upon infant mortality.

\section{Conservative Censoring}

The number of observations are reduced with conservative censoring, particularly the number of deaths. Except for children born out of wedlock, whose surplus mortality was reduced to 1.5 , the effects of the other variables are almost the same as with radical censoring. With conservative censoring the estimate of the surplus mortality of the illegitimate children changes little when social group is added to the variables, because so many of these children are missing from the analysis even before the social class variable is added. Illegitimate children are probably underrepresented in life tables based on family reconstitutions, which means that the mortality figures from these studies may be too low. The size of this gap is difficult to determine.

If we compare the results obtained by radical and conservative censoring, we find that, except for the effects of being born out of wedlock, other variables are quite similar, but the p-values are better with the radical censoring. If the analysis is lim- 
ited to children born within marriage, it is definitely an advantage to choose radical censoring.

\section{Another Test of the Effect of Social Class on Infant Mortality}

Having chosen radical censoring, I wanted to pursue the issue of a possible relationship between social class and infant mortality. Infant mortality for two groups of legitimate children born at the beginning of the nineteenth century was studied. This was the time when infant mortality was highest, and if a difference existed between social groups, it should have appeared during this period. The wealthy group consisted of farmers who had large farms in the land register of 1838 . The limit was set at four times as much as for the first classification (Four daler in tax). A higher limit would have reduced the number of observations too much. The other group was children of fathers with the lowest social code in the census of 1825 , i.e., excluding those who were originally coded as belonging to the middle class. The reason to choose this census rather than the 1835 census was that the land register refers to the situation many years before it was printed. It is important for the sake of comparison that the children in the two groups were born at about the same time.

The birth years turned out to be very evenly distributed among the two groups. The median birth year for the children of the wealthy farmers was 1827 , while for the other group the median year of birth was 1825 . Only the children born before 1840 were included in the analysis. There were a total of 384 children in the wealthy group, and 1,920 in the other group. The results of the analysis show no significant relationship between social group and infant mortality.

\section{Concluding Remarks}

Examination of the data set showed that the problems of stillbirths needed to be dealt with. My choice was not to include the stillbirths, but to exclude the children who lived less than two days.

It is bold to assume that all the children who were not registered as dead in the burial lists survived their first birthday, but the comparison between the results of this assumption and a more conservative assumption based on the principles of family reconstitution justifies the radical assumption, at least for the majority of children, that is those who were born within wedlock. The advantage of such an assumption is the more efficient use of laboriously collected data. In family reconstitution children born out of wedlock often disappear in the analysis. 
The higher mortality of illegitimate children was hardly surprising. More unpredictable was the outcome of the social class variable. Thus far earlier studies of individual Norwegian parishes have not shown clearcut patterns of social differences, but the data sets have been small and the method of analysis has not been the most efficient. Nor did the present study, utilizing a large data set and a more refined method of analysis, result in a correlation between social group and mortality. It is possible that there are weaknesses in the coding of social class, but if an important correlation existed, there should have been some signs of it. The conclusion must be that, if there was such a correlation, it must have been very weak.

The only Norwegian analysis based upon a large data set is the study of infant mortality in the randomly chosen 45 parishes around 1800, and it shows that mortality was positively correlated with high social class. The author points out that wealthier persons had larger households and indicates that the risk of infection might have been higher in these households.

Conventional wisdom relates the mortality decline to improved welfare and living conditions. An improvement in welfare is difficult to measure, but even if the landless classes increased during the nineteenth century, it is commonly believed that there was an improvement in living conditions at the same time, at least in the countryside. In Asker and Bærum no difference in infant mortality between the two social classes was found. This may mean that there was no relationship between improved living conditions and infant mortality, or that the positive effects of the improvement were marginal compared to all the perils to which an infant was exposed. Another plausible explanation is that the improvement was so general that both social classes benefited from it.

In recent research there has been a focus on cultural causes for the decline in infant mortality, for example, changes in the care of young children. In her doctoral dissertation from 1997, Margunn Skjei Knutsen has made a valuable contribution by bringing to light literature on child care around the end of the eighteenth century. ${ }^{16}$ The weak point in the analysis is the connection between the possible new ideas among the small numbers of the literate elite of Trondheim and the practice of the common people in the town. The time elapsed between the arrival of the literature in Norway and the improvement in child mortality seems to be too short to argue for a causal effect. In Asker and Bærum, where there were practically no doctors or midwives to promote new ideas on child care, as opposed to the situation in Trondheim, infant mortality also declined.

There is probably not one single cause for the decline in infant mortality during the nineteenth century in Norway, nor in Scandinavia for that matter, but if we

16 Margunn Skjei Knudtsen, Fra frelse til helse. Spedbarnsdødelighet og omsorgssyn i Norge ca. 1700-1830 med sarlig vekt på forholdene i Var Frue sokn, Trondheim (Ph. D. thesis, NTNU, Historisk institutt, 1997). 
find an almost simultaneous decline in many local communities, care must be shown not to select particular explanations for each community, unless there are quite specific local circumstances warranting such an explanation. We have not yet found the primary cause, or the combination of causes of the decline in infant mortality during the nineteenth century.

Eli Fure is Senior Archivist at the National Archives of Norway, Folke Bernadottes vei 21, Postboks 4013 Ullevål stadion, 0806 Oslo, Norway. 